\title{
Bacteriological Profile of Community Acquired Urinary Tract Infections and Antibiotic Susceptibility of Gram Negative Isolates
}

\author{
B. Lakshmi ${ }^{1}$, Himabindu Mantravadi ${ }^{2 *}$ and Rohini ${ }^{1}$ \\ ${ }^{1}$ Department of Microbiology, MNR Medical College and Hospital, \\ Fasalwadi, Sangareddy, Telangana, India \\ ${ }^{2}$ Department of Microbiology, Mallareddy Institute of Medical Sciences, \\ Suraram, Hyderabad, Telangana, India \\ *Corresponding author
}

\section{A B S T R A C T}

\begin{tabular}{|c|c|}
\hline Keyword & $\begin{array}{l}\text { it the most common infections encountered in clinical } \\
\text { ailability of antibiotics, UTI remains the most common }\end{array}$ \\
\hline $\begin{array}{l}\text { Community } \\
\text { acquired UTIs, } \\
\text { Antibiotic } \\
\text { sensitivity, } \\
\text { Drug resistance, } \\
\text { Imipenem, } \\
\text { Meropenem. }\end{array}$ & $\begin{array}{l}\text { bacterial infection in the human population. UTI is predominantly a disease of females and } \\
\text { is frequently acquired through the community. One of the common causes of } \\
\text { uncomplicated community acquired UTIs is Escherichia coli. However the bacteria } \\
\text { causing UTI may vary according to the different geographical areas. Hence we have } \\
\text { undertaking this study to assess the prevalence of bacteria that causes community acquired } \\
\text { UTIs and their antibiotic sensitivity pattern. } 500 \text { Mid-stream urine samples were processed } \\
\text { and } 108 \text { bacterial isolates were isolated and processed for their antibiotic sensitivity profile }\end{array}$ \\
\hline Article Info & \\
\hline $\begin{array}{l}\text { Accepted: } \\
\text { 04 October } 2017 \\
\text { Available Online: } \\
10 \text { December } 2017\end{array}$ & $\begin{array}{l}\text { atibiotics, Norfloxacin is least sensitive }(16.67 \%) \text {. Antibiotics with good sensitivity are } \\
\text { nipenem }(100 \%) \text { and Meropenem }(100 \%) \text {. Community acquired Urinary Tract Infections } \\
\text { e most commonly seen in Females than in Males in our study and most commonly } \\
\text { aused by Escherichia coli. Drug resistance is not much seen in our study. }\end{array}$ \\
\hline
\end{tabular}

\section{Introduction}

Urinary tract infections (UTI) are amongst the most common infections encountered in clinical practice and also the most common of the bacterial infections that leads patients to seek medical care (Palac, 1986). Approximately $10 \%$ of humans will have an episode of UTI at some point of time during their lives. This is also the most common hospital acquired infection, accounting for as many as $35 \%$ of nosocomial infections (Steven, 1989). $1 \times 10^{5}$ organisms/ml of a single bacterium corresponds to the presence of UTI. Urinary tract infection is predominantly a disease of females. Nearly $30 \%$ of women will have had a symptomatic UTI requiring antimicrobial therapy by age 24 and almost half of all women will experience a UTI during their life time (Mabeck, 1972).

Amongst several antimicrobial agents used for treatment of UTIs beta-lactam antibiotics have been the most trusted and useful agents 
for many years. However, resistance to these antibiotics has been acquired by bacteria like Escherichia coli and Klebsiella, throughout the world (Singh et al., 1997). The vast majority of urinary tract infections (UTIs) are caused by a single organism from a very limited spectrum of bacteria. In uncomplicated cases, the organism is almost always Escherichia coli or S. saprophyticus whereas in complicated cases, the spectrum is more diverse, encompassing several Enterobacteriaceae and Gram-positive organisms such as Enterococci (Gaterman and Stamm, 1998, 2005).

Resistance to antimicrobial agents was recognized more than 50 years ago. Since then it continues to be a major cause for increased morbidity, mortality and health care cost (Ang et al., 2004). Earlier, drug resistant organisms were found in tertiary care centers and referral hospitals where the risk factors for their emergence were high. Many a times, this is because the treatment for them is empirical. But their recent isolation from the community has been a cause for concern. Drug resistant organisms like ESBLs from the community are discovered predominantly in patients with urinary tract infections (Johann et al., 2005). Thus a knowledge of the bacterial profile and the antibiotic susceptibility pattern is essential to monitor the treatment and thus avoid the emergence of resistance among the bacteria (Macgree et al., 1999).

The present study was thus designed to detect the bacteria and their antibiotic sensitivity and resistance pattern among patients with UTI.

\section{Materials and Methods}

This prospective study was conducted by the department of Microbiology on patients with urinary tract infections, attending MNR Medical College and Hospital, Fasalwadi,
Sangareddy dist after taking the institutional ethical committee approval. The study period was from September 2013 to February 2014. 500 Midstream samples of urine (MSU) from clinically suspected cases of Urinary Tract Infection attending the out- patient and inpatient Departments of MNR Medical College and Hospital were included in the present study. The clinical symptoms included patients with burning micturition, dysuria, frequency, urgency, suprapubic pain, fever with or without chills, haematuria and loin pain for duration of one week. Cultures yielding no growth, insignificant growths, patients with hospital acquired UTI were excluded from the study.

Clean catch, Mid-Stream Urine was collected in sterile universal container, transported to the laboratory as soon as possible taking sterile precautions and processed with in 1 hour. History of patients, prior antibiotic therapy, catheterization, any instrumentation, recent major or minor surgery on kidney or urinary tract etc. was recorded. Urine was processed soon after collection in order to minimize multiplication of any contaminating organisms if present.

Part of sample - was well mixed and using a standard loop, which delivers a volume of $0.001 \mathrm{ml}$ of urine, was inoculated on to solid medium like Blood agar, MacConkey agar (Frimodt -Moller et al., 2001), and the inoculated plates were aerobically incubated at $37^{\circ} \mathrm{C}$ for $24-48$ hours. Accordingly, 100 or $>100$ colonies correspond to $10^{5}$ or $>10^{5}$ $\mathrm{cfu} / \mathrm{ml}$ respectively. Colony count is multiplied with 1000 in order to give estimate of the organisms per $\mathrm{ml}$ of urine. Colonies were further processed by doing Gram's stain. Further identification and confirmation of organisms were done by the standard identification tests as described in Mackie and McCartney practical medical microbiology $14^{\text {th }}$ edition. 
Antibiotic sensitivity tests were done by Kirby-Bauer disk diffusion method. The test organism is subcultured into peptone water and incubated for 4-6 hours at $37{ }^{0} \mathrm{C}$. The turbidity is standardized with 0.5 McFarland, and is swabbed over $90 \mathrm{~mm}$ Mueller Hinton agar plate. Antibiotic disks were placed 15 $\mathrm{mm}$ from the edge of the plate and disks are evenly placed and incubated at $37^{\circ} \mathrm{C}$ for $18-$ 24 hours. Zones of inhibition were measured with a ruler and interpreted as per NCCLs guidelines (Wayne, 2009). The commercially available antibiotic disks supplied by High media (Mumbai) were used.

The panel of antibiotics used was Cotrimoxazole- $25 \mu \mathrm{g}$, Norfloxacin- $10 \mu \mathrm{g}$, Nalidixic Acid- $30 \mu \mathrm{g}$, Nitrofurantoin- $300 \mu \mathrm{g}$ Ciprofloxacin-5 $5 \mathrm{~g}, \quad$ Levofloxacin-5 $\mu \mathrm{g}$, Gentamicin- $10 \mu \mathrm{g}$, Amikacin - 30 $\mathrm{g}$, Ceftriaxone- 30 , ceftazidime $30 \mu \mathrm{g}$,

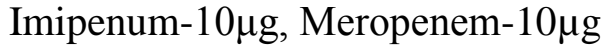

\section{Results and Discussion}

A total of 500 mid-stream urine samples were processed and 108 organisms were isolated from them (Table 1). Culture positive cases were predominant in females with 73 cases (68\%) than in males with 35 cases (32\%) (Fig. 1). Escherichia coli is the most common isolate (68) followed by Coagulase negative Staphylococci (13), Klebsiella pneumoniae (09), Proteus mirablis (08), Pseudomonas spp (06), Citrobacter (02), Enterococci (02) (Table 2). Antibiotic sensitivity pattern of 12 different antibiotics were done in the study. All the isolates are sensitive to Imipenum and Meropenum (100\%), followed by Levofloxacin (74.1\%) and Amikacin (71.3\%) (Table 3).

Prevalence of Drug resistant organisms varies widely in different regions of India. Recently emergence of drug resistant organisms like ESBLs from the community has led to increased concern among clinicians. Patients from remote areas in and around Sangareddy come to our hospital without any prior treatments. Antibiotic resistance organisms are not prevalent in our hospital.

As there was no data available on antibiotic sensitivity pattern of common bacteria that would help clinicians in treating infections effectively, this study was undertaken.

Table.1 Distribution of culture positive and negative cases

\begin{tabular}{lll}
\hline TOTAL CASES & NUMBER OF CULTURE & NUMBER OF CULTURE \\
& POSITIVE CASES $(\boldsymbol{\%})$ & NEGATIVE CASES $(\boldsymbol{\%})$ \\
\hline 500 & $108(21.6 \%)$ & $392(78.4 \%)$ \\
\hline
\end{tabular}

Table.2 Distribution of organisms causing UTI

\begin{tabular}{lll}
\hline ORGANISMS ISOLATED & TOTAL STRAINS ISOLATED (X) & PERCENTAGE OF INCIDENCE (X/108) \\
\hline Escherichia coli & 68 & $63 \%$ \\
K. pneumonia & 09 & $8.3 \%$ \\
Citrobactor spp & 02 & $1.9 \%$ \\
Proteus mirabilis & 08 & $7.4 \%$ \\
Pseudomonas aeruginosa & 06 & $5.6 \%$ \\
Enterococci & 02 & $1.9 \%$ \\
CoNS & 13 & $12 \%$ \\
TOTAL & 108 & $100 \%$ \\
\hline
\end{tabular}


Table.3 Overall antibiotic sensitivity pattern

\begin{tabular}{lll}
\hline ANTIBIOTIC & \% SENSITIVE & \% RESISTANT \\
\hline Co-trimoxazole & 35.20 & 64.8 \\
Norfloxacin & 16.67 & 83.33 \\
Nalidixic Acid & 40.74 & 59.26 \\
Nitrofurantoin & 67.59 & 32.41 \\
Ciprofloxacin & 69.50 & 30.50 \\
Levofloxacin & 74.10 & 29.90 \\
Gentamicin & 64.81 & 35.19 \\
Amikacin & 71.30 & 28.70 \\
Ceftazidime & 46.30 & 53.70 \\
Ceftriaxone & 44.55 & 55.55 \\
Imipenum & 100.00 & 0.00 \\
Meropenum & 100.00 & 0.00 \\
\hline
\end{tabular}

Fig.1 Distribution of culture positive cases based on sex

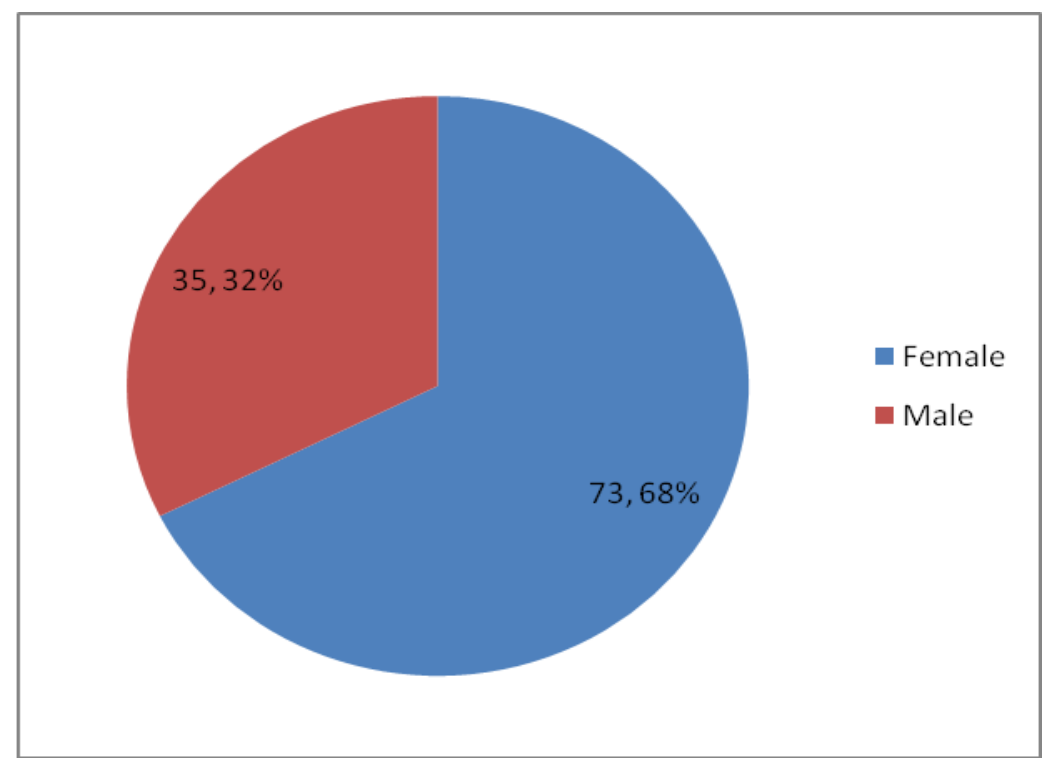

The present study revealed a female predominance among the subjects which correlated well with the studies of Das et al., (1982), Gales et al., (1998) and Modarres et al., (1997). Among the organisms isolated in the study, Escherichia coli was the most frequent pathogen being isolated in $63 \%$ of the cases and Klebsiella spp. in $8.3 \%$ of the cases. Wattal et al., (2005) in their study in New Delhi isolated Escherichia coli in 59\% of the cases and Klebsiella spp in $10.2 \%$ of the cases. Babypadmini et al., (2004) from
Chennai reported 49\% Escherichia coli and 8\% Klebsiella spp (Babypadmini, 2004), (Supriya et al., 2004). Chan et al., reported $61 \%$ E. coli and 16\% Klebsiella spp (Chan, 1987).

However, Das et al., (1982) reported Klebsiella spp. as the most common pathogen causing urinary tract infection in hospitalized patients but even in this study, Escherichia coli was responsible for most of the infections among outpatients (Das, 1982). 
High sensitivity pattern was noted towards Amikacin (73.1\%) and Gentamicin (64.8\%), which were in accordance to the work done by other authors (Kritu Panta, 2013) (Seyedah Afrooz Azmil et al., 2014). All isolates (100\%) were susceptible to Imipenem and Meropenem (Jaya Sankarankutty et al., 2014), (Iraj Alipourfard Iraj Alipourfard, 2010). Quinolones were highly effective in our study.

Community acquired Urinary Tract Infections are most commonly seen in Females than in Males in our study and most common causative organism is Escherichia coli. Drug resistance is not much seen in our study. Escherichia coli (68\%) was the commonest pathogen responsible for Community acquired urinary tract infection. Quinolones seems a reasonable alternative to Cephalosporins for the treatment of community acquired urinary tract infections.

\section{References}

Ang JY, Ezike E, Asmar BI. Symposium on infections- Old and New-II; Indian J Pediatr; 2004; 71 (3); 229-239

Babypadmini S, Appalaraju B. 2004. Extended spectrum beta lactamases in urinary isolates of Escherichia coli and Klebsiella pneumoniae- prevalence and susceptibility pattern in a tertiary care hospital. Indian J Med Microbiol; 22 (3): 172-174.

Chan DTM, Chan KM et al., 1987. Urinary tract infection in a female medical ward. Journal of the Hong Kong Medical Association Vol. 39. No. 4,

Clinical and Laboratory standard institute (CLSI) Analysis and Presentation of cumulative antimicrobial susceptibility test data. $3^{\text {rd }}$ ed. Approved guidelines M39-A3. Wayne PA, CLSI 2009

Das NK, Vaze S et al., 1982. The bacteriology of urinary tract infection and its relationship with different pathological conditions. J. Com. Dis., 14(4): 251-255.

Frimodt -Moller, N. and Espersen, F.2001. Evaluation of calibrated 1 and $10 \mu \mathrm{l}$ loops for detection of low count bacteriuria in vitro. APMIS, 108, 525530

Gales AC, Jones RN et al., 2000. Activity and spectrum of 22 antimicrobial agents tested against urinary tract infection pathogens in hospitalized patients in Latin America; report from second year of the SENTRY Antimicrobial surveillance program (1998). J Antimicrob Chemother. 45, 295-303.

Gaterman S.G. "Bacterial infections of the urinary tract". Topley and Wilson's Microbiology and Microbial infections. Bacteriology Vol I, 10th edition, Tata McGrawHill publishers; 672- 683

Iraj Alipourfard, Nilufar Yeasam Nili. 2010Antibiogramof extended spectrum beta lactamase producing Escherichia coli and Klebisella pneumoniae isolated from hospital sample, Bangladesh $\mathbf{J}$ Med Microbiol. 4(10): 32-36.

Jaya Sankarankutty, Soumya Kaup. 2014. Distribution and antibiogram of gram negative isolates from various clinical samples at a Teaching Hospital, Tumkur. SchJAppMedSci., 2(3): 92731.

Johann DPP, Nordmann P et al., 2005. Emergence of Enterobacteriaceae producing Extended spectrum Beta lactamases (ESBLs) in the community. J Antimicrob Chemother 56, 52-59.

Kritu Panta, Prakash Ghimire, Shiba Kumar Rai, et al., 2013. Antibiogram typing of gram negative isolates in different clinical samples of a Tertiary Hospital. Asia J Pharm Clin Res., 6(1): 153-56.

Mabeck, 1972. Mabeck CE: Treatment of uncomplicated urinary tract infection in non-pregnant women. Postgrad Med J: 


\section{8:69-75}

Mackie and Mc Cartney Practical Medical Microbiology $14^{\text {th }}$ edition, Pp. 86-88.

Magree JT, Pritchard EL, Fitzgerald KA. 1999. On behalf of the Welsh Antibiotic Study Group. Antibiotic prescribing and antibiotic resistance in the community practice: retrospective study, 1996-8. BMJ 319:1239-40.

Modarres S et al., 1997. Bacterial etiologic agents of urinary tract infection in children in the Islamic Republic of Iran, Eastern Mediterranean Health Journal, 3(2): 290-295.

Palac DM. 1986.Urinary tract infections in women: a physician perspective, Lab med 17:25,

Seyedah Afrooz Azmil, Shahram Boroumandi, Mohammad Rahbar. 2014. Prevalence of drug resistant pattern in admitted patients to pars hospital, Tehran, Iran. IJBSCI. 2(1); 14-21

Singh et al., 1997. Comparative evaluation of two tests for betalactamase in Escherichia coli by Indian journal of medical microbiology 15 (4): 205 - 206

Stamm W E 1998. Urinary tract infections; Hospital infections, 4th edition, Lippincott-Raven Publishers, Philadelphia. 477-485

Stamm W E. 2005 Urinary tract infections and pyelonephritis. Harrison's principles of internal medicine. Vol 2, McGraw Hill publishers; 1715-1721

Steven's M 1989. Screening urines for bacteriuria, Med lab Sci. 46:194,

Supriya S et al., 2004. Evaluation of extended spectrum beta lactamase in urinary isolates. Ind J Med Res; 120, December, 553-556

Wattal C et al., 2005. ESBL- An emerging threat to antimicrobial therapy. Microbiology Newsletter. Sir Ganga Ram Hospital, Vol 10, No 1. 1-8.

\section{How to cite this article:}

Lakshmi, B., Himabindu Mantravadi and Rohini. 2017. Bacteriological Profile of Community Acquired Urinary Tract Infections and Antibiotic Susceptibility of Gram Negative Isolates. Int.J.Curr.Microbiol.App.Sci. 6(12): 254-259. doi: https://doi.org/10.20546/ijcmas.2017.612.031 